\title{
O complexo holosericeus de Ommatius Wiedemann no Brasil: nova espécie e primeiro registro do grupo ampliatus para o País e novos registros para o grupo holosericeus (Diptera, Asilidae)
}

\author{
Rodrigo Vieira ${ }^{1}$, Freddy Bravo $^{2} \&$ José Albertino Rafael $^{1}$
} ${ }^{1}$ Programa de Pós-graduação em Entomologia, Instituto Nacional de Pesquisas da Amazônia, Caixa Postal 478, 69060-001 Manaus-AM, Brasil.
rodrigo08vieira@gmail.com, jarafael@inpa.gov.br
${ }^{2}$ Universidade Estadual de Feira de Santana, Departamento de Ciências Biológicas, Av. Transnordestina S/N, Bairro Novo Horizonte, 44036-900 Feira
de Santana-BA, Brasil. fbravo@uefs.br

\begin{abstract}
The holosericeus complex of Ommatius Wiedemann in Brazil: a new species and first record of the ampliatus group for the country and new records for the holosericeus group (Diptera, Asilidae). In this paper a new species of Ommatius Wiedemann, 1821 belonging to the ampliatus group is described from the Amazonas state. Furthermore, new records, taxonomic variations, illustrations and description of male and female terminalia are provided for the species of the holosericeus group.
\end{abstract}

KEYWORDS. Neotropical; Ommatiinae; South America; Taxonomy.

RESUMO. O complexo holosericeus de Ommatius Wiedemann no Brasil: nova espécie e primeiro registro do grupo ampliatus para o país e novos registros para o grupo holosericeus (Diptera, Asilidae). Neste trabalho é descrita uma nova espécie de Ommatius Wiedemann, 1821 para o estado do Amazonas, pertencente ao grupo ampliatus. Além disso, são fornecidos novos registros, variações taxonômicas, ilustrações e descrição das estruturas das terminálias masculina e feminina para as espécies do grupo holosericeus.

PALAVRAS-CHAVE. América do Sul; Neotropical; Ommatiinae; Taxonomia.

Scarbrough (2002) definiu o complexo de espécies holosericeus do gênero Ommatius Wiedemann, 1821, baseado principalmente na presença de uma cerda anepimeral proeminente. O complexo holosericeus é formado pelos grupos ampliatus e holosericeus. Dentre outras características, nas espécies do grupo holosericeus, o fêmur posterior do macho possui cerdas similares no comprimento e na espessura, desde a sua base até o ápice, epândrio com uma projeção dorsal pré-apical e as cápsulas das espermatecas das fêmeas muito mais longas do que largas. No grupo ampliatus, as cerdas do fêmur posterior são longas e grossas na base e as demais curtas e finas, epândrio sem projeção dorsal préapical e as cápsulas das espermatecas das fêmeas, no máximo levemente mais longa do que larga (Scarbrough 2002).

O grupo ampliatus é constituído de 20 espécies, com registros desde a região central do México até o norte da Argentina. O grupo holosericeus é constituído de seis espécies, sendo cinco delas com registros no Brasil, todas tratadas neste trabalho e com registros adicionais para Galápagos, Peru e norte da Argentina (Lamas 1972; Scarbrough 2002; Papavero 2009).

Neste trabalho, é descrita uma espécie nova do grupo ampliatus proveniente do estado do Amazonas e são fornecidos novos registros geográficos e ilustrações das terminálias das espécies brasileiras do grupo holosericeus.

\section{MATERIAL E MÉTODOS}

Foram examinados exemplares provenientes das seguintes instituições: DZUP - Coleção Entomológica Padre Jesus Santiago Moure, Universidade Federal do Paraná, Curitiba, Paraná; INPA - Coleção de Invertebrados do Instituto Nacional de Pesquisas Amazônia, Manaus, Amazonas; MNRJ Museu Nacional do Rio de Janeiro, Rio de Janeiro; MZUSP - Museu de Zoologia da Universidade de São Paulo, São Paulo.

Para a realização do estudo dos espécimes, a terminália foi destacada e diafanizada com solução aquosa de hidróxido de potássio $(\mathrm{KOH}) 10 \%$, por tempo variado dentro de uma estufa a $50^{\circ} \mathrm{C}$, a depender do grau de esclerotização da mesma. Posteriormente, a terminália foi transferida para a água por 10 minutos, depois para uma solução de ácido acético a $10 \%$ e em seguida transferida para uma lâmina escavada contendo glicerina. Após estudo e ilustração, a terminália foi acondicionada em microtubo contendo glicerina e este foi afixado ao alfinete do espécime correspondente.

A terminologia adotada segue Cumming \& Wood (2009). Neste trabalho, são fornecidas ilustrações detalhadas das estruturas da terminália em ângulos omitidos por Scarbrough (2002) e que mostram diferentes formas nas novas vistas, importantes para a identificação dos espécimes. 
Para a relação dos dados das etiquetas dos espécimes, os nomes dos países foram colocados em letras maiúsculas, os estados em negrito, os meses de coletas em algarismo romano minúsculo e o número de espécimes, sexo e a instituição à qual pertencem em negrito e entre parênteses (). Os dados de cada etiqueta dos espécimes foram separados por uma barra/e as informações úteis adicionais, não encontradas nestas, foram colocadas entre colchetes [], sempre que possível. Além disso, correções de dados das etiquetas foram informadas através de chaves \{\} .

\section{RESULTADOS E DISCUSSÃO}

Foram analisados seis espécimes pertencentes a uma espécie do grupo ampliatus e 44 espécimes pertencentes a cinco espécies do grupo holosericeus.

\section{Grupo ampliatus}

Este grupo de espécies foi definido por Scarbrough (2002).

\section{Ommatius aubreyi Vieira, Bravo \& Rafael sp. nov.} (Figs. 1-7)

Diagnose: fêmur posterior com 1/4 basal castanho-amarelado e 3/4 apical castanho (Fig. 3); tergito IX+X ventralmente com duas projeções direcionadas para o esternito VIII (Fig. 5); margem posterior do esternito VIII proeminente medialmente (Fig. 7).

Holótipo Fêmea.

Cabeça: antena castanha (Fig. 2); vértice com pruinosidade dourada; duas cerdas ocelares; face com pruinosidade acinzentada (Fig. 2); místax com sete cerdas castanhas; fronte castanha com pruinosidade dourada; palpo com cerdas castanhas e amareladas; probóscide preta com cerdas ventrais brancas; cerdas labiais castanhas; occipício com tomento cinza; cerdas occipitais esbranquiçadas; cinco cerdas pós-oculares acima de cada olho da cabeça.

Tórax: margem lateral do antepronoto com tomento cinza e a região mediana com tomento dourado, três cerdas amareladas antepronotais; pós-pronoto com tomento cinza; lobo pós-pronotal castanho; mesonoto preto; mancha póshumeral dourada; calo pós-alar e parede pós-alar castanhos; duas cerdas notopleurais; dois pares de cerdas dorsocentrais; uma cerda pós-alar; uma cerda supra-alar; duas cerdas marginais escutelares; uma cerda anepimeral castanha; cerdas do meron posterior + metaepisterno e do catatergito amareladas; pleura com tomento cinza (Fig. 1).

Asa: veia costal sem dilatação na porção mediana; veia r$\mathrm{m}$ situada um pouco além do meio da célula discal; bifurcação de $\mathrm{R}_{4+5}$ situada um pouco além do ápice da célula discal. Halteres amarelados.

Pernas: trocânter posterior com três cerdas amareladas; coxas mediana e posterior com uma cerda grossa e amarelada na lateral; fêmures anterior e mediano ventralmente amarelado (Fig. 1), anteriormente em maior parte castanho, posteriormente amarelado com uma pequena parte do ápice castanha; fêmur posterior com $1 / 4$ basal castanho-amarelado e 3/4 apical castanho (Fig. 3); fêmur anterior da perna esquerda com uma cerda castanha na região anterior, ventralmente somente com cerdas longas, finas e amareladas; fêmur mediano com duas a três cerdas anteriores, uma a duas cerdas anteroventrais, uma a duas cerdas longas, finas e amareladas posteroventrais na região basal, cerda posterodorsal pré-apical grossa e preta; fêmur posterior com três cerdas anteriores pretas, três a quatro cerdas anteroventrais pretas, quatro cerdas pretas posteroventrais; tíbia anterior amarelada com o ápice acastanhado; tíbia mediana amarelada com 1/6 apical castanho; tíbia posterior com aproximadamente metade basal amarelada e metade apical castanha; tarsômero basal anterior amarelado, do tarso mediano amarelado com o ápice acastanhado e do tarso posterior castanho; tarso anterior esquerdo somente com cerdas escuras e o direito com uma cerda amarelada.

Abdômen: cerdas laterais do tergito I amareladas; tergitos castanhos dorsalmente, bordas laterais pretas com tomento cinza; esternitos castanho-escuros, com tomento cinza.

Terminália: tergito IX $+\mathrm{X}$ largo (Fig. 4), ventralmente com duas projeções direcionadas para o esternito VIII (Fig. 5); três cápsulas das espermatecas arredondadas e com a superfície rugosa (Fig. 6); margem posterior do esternito VIII proeminente medialmente e margem anterior com uma reentrância medial (Fig. 7).

Comprimento do holótipo: corpo 9,8 mm; asa 8,4 mm.

Condição do holótipo: uma cerda ocelar, uma cerda dorsocentral esquerda e duas direitas, cerda supra-alar e pósalar direita, cerda marginal escutelar direita, tarsômeros 3-5 da perna anterior direita perdidos; ápice da asa direita dobrado; parte do abdômen e terminália em microtubo com glicerina. Microtubo alfinetado junto ao espécime.

Macho: desconhecido.

Variação: três parátipos possuem a face dourada; parátipos com seis a oito cerdas no místax; quatro parátipos com quatro cerdas pós-oculares acima de cada olho e um parátipo com sete cerdas acima do olho direito e seis acima do olho esquerdo; quatro cerdas amareladas antepronotais; dois parátipos possuem a cerda anepimeral amarela; um parátipo com três cerdas do lado esquerdo e um parátipo com três do lado direito; um parátipo com três cerdas anteriores, sendo uma amarela e duas pretas, no fêmur posterior; um parátipo possui seis cerdas pretas posteroventrais no fêmur posterior; quatro parátipos somente com cerdas pretas no tarso anterior; comprimento do corpo entre $8,5 \mathrm{~mm}$ e $12,4 \mathrm{~mm}$ e asa entre 8,0 mm e 10,3 $\mathrm{mm}$.

Etimologia: o nome aubreyi é dedicado ao Dr. Aubrey Scarbrough, especialista em Ommatiinae.

Comentários: dentre as espécies do grupo ampliatus, Ommatius aubreyi sp. nov., pode ser separada de $O$. angustatus Scarbrough, 2002, O. destitutus Scarbrough, 2002, O. fernandezi Scarbrough, 2002, O. triangularis Scarbrough, 2002, O. tucumanensis Scarbrough, 2002 e O. unguiculatus Scarbrough, 2002 pela coloração do fêmur posterior (Fig. 

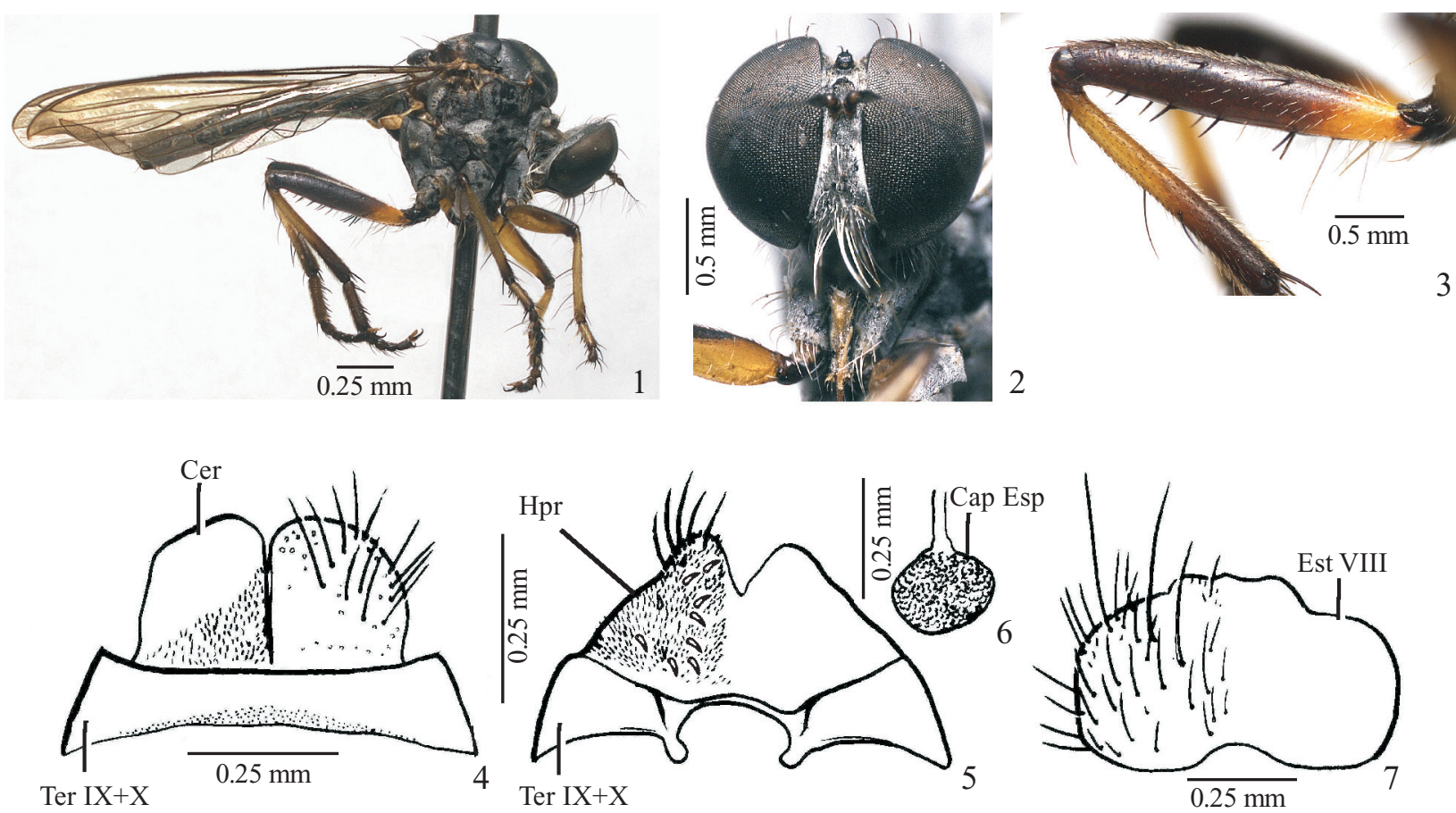

Figs. 1-7. Ommatius aubreyi Vieira, Bravo \& Rafael sp. nov. 1. Holótipo: hábito lateral; 2. Holótipo: cabeça, vista frontal; 3. Holótipo: fêmur posterior; 4. Parátipo: tergito IX $+X$ e cercos em vista dorsal; 5. Parátipo: tergito IX+X em vista ventral e hipoprocto; 6. Holótipo: cápsula da espermateca; 7. Holótipo: esternito VIII. Abreviaturas: Cer: Cercos; Cap Esp: Cápsula da espermateca; Hpr: Hipoprocto; Est VIII: Esternito VIII; Ter IX+X: Tergito IX+X.

3). Em O. aubreyi sp. nov., a maior parte do fêmur posterior é castanho (Fig. 3), enquanto que, nas espécies citadas acima, a maior parte do fêmur posterior é amarelado.

Ommatius aubreyi sp. nov., diferencia-se de O. ampliatus Scarbrough, 2002, O. angulosus Scarbrough, 2002, O. ayalai Scarbrough, 2002, O. dolabriformis Scarbrough, 2002, $O$. flexus Scarbrough, 2002, O. gladiatus Scarbrough, 2002, O. ovatus Scarbrough, 2002, O. quadratus Scarbrough, 2002, O. tanpadiensis Scarbrough, 2002 e O. tropidus Scarbrough, 2002 por possuir todas as cerdas anteroventrais do fêmur posterior pretas (Fig. 3), enquanto que, nessas espécies, a maioria destas cerdas são amareladas ou brancas.

Ommatius aubreyi sp. nov., distingue-se de $O$. constrictus Scarbrough, 2002, O. depressus Scarbrough, 2002 e $O$. lunatus Scarbrough, 2002 por possuir algumas cerdas amareladas no palpo. Nas demais espécies acima, todas as cerdas do palpo são pretas.

Ommatius aubreyi sp. nov., difere de O. bullatus Scarbrough, 2002 por possuir as cápsulas das espermatecas arredondadas (Fig. 6) e o tergito IX+X largo dorsalmente (Fig. 4). Em $O$. bullatus, as cápsulas das espermatecas são ovais e o tergito IX+X é estreito dorsalmente e possui as bordas pontiagudas.

Registros Geográficos: BRASIL - Amazonas.

Material tipo examinado: Holótipo fêmea. BR[ASIL], AM[azonas], Manaus, ZF-03, BR 174 Km 41 Res.[erva] 1501 [do Projeto Dinâmica Biológica de Fragmentos Florestais], 02²7’26”'S, 594’00”W/15-25.xi.1995, Rocha e Silva, L.E.F. col.[etores]/[Armadilha] Malaise/0061297/Holótipo Ommatius aubreyi Vieira, Bravo \& Rafael (INPA).

Parátipos: BR[ASIL], AM[azonas], Manaus, ZF-03, Faz.[enda]. Es- teio, 11.vi.1986, Klein, Bert col.[etor]/[Reserva] 1113 [do Projeto Dinâmica Biológica de Fragmentos Florestais] 2²3'03"S 5951'03"W, Armadilha Malaise, R.C.E. [rede central leste]/0020679 (1\% INPA); BR[ASIL], AM[azonas], Manaus, ZF-03, Faz.[enda] Esteio, 18.iii.1986, Klein, Bert col.[etor]/1208 Cidade Powell 2²2'34'S 58 52'39”W, Armadilha Malaise, R.C.N. [rede central norte]/00020270 (10 INPA); BRA[SIL], Amazonas, Manaus, ZF-03, Km 23, Faz.[enda] Esteio, Res.[erva] 1208, 15.iv.1987, (R.L.E) [rede lateral leste]/[Armadilha] Malaise, B.C. Klein, Leg. (1 INPA); BR[ASIL], AM[azonas], Manaus, ZF-03, Faz.[enda] Esteio, 01.iv.1986, Klein, Bert col.[etor]/1208 Cidade Powell 2'22'34'S 5852'39'W, Armadilha Malaise, R.C.N. [rede central norte]/0020725 (10 MZUEFS); BR[ASIL], AM[azonas], Manaus, ZF-03, Faz.[enda] Esteio, 11.ii.1986, Klein, Bert col.[etor]/1208 Cidade Powell 2²2'34”S 58 52'39”W, Armadilha Malaise, R.C.S. [rede central sul]/00020261 (19 MZUEFS).

\section{Grupo holosericeus}

Este grupo de espécies foi definido por Scarbrough (2002).

\section{Ommatius conus Scarbrough}

(Figs. 8-19)

Ommatius conus Scarbrough, 2002: 204, figs. 168, 182-190; Papavero 2009: 48 (catálogo).

Diagnose. Macho: tíbia mediana com cinco a seis cerdas pretas e fortes na região anterior, esternito VII com uma projeção em forma de cone; cercos alongados e truncados apicalmente (Fig. 14); esclerito subepandrial com duas projeções longas e digitadas (Fig. 19). Fêmea: tergito IX+X membranoso na porção mediana (Fig. 15); esternito VIII com duas concavidades ao lado da margem posteromedial (Fig. 17). 


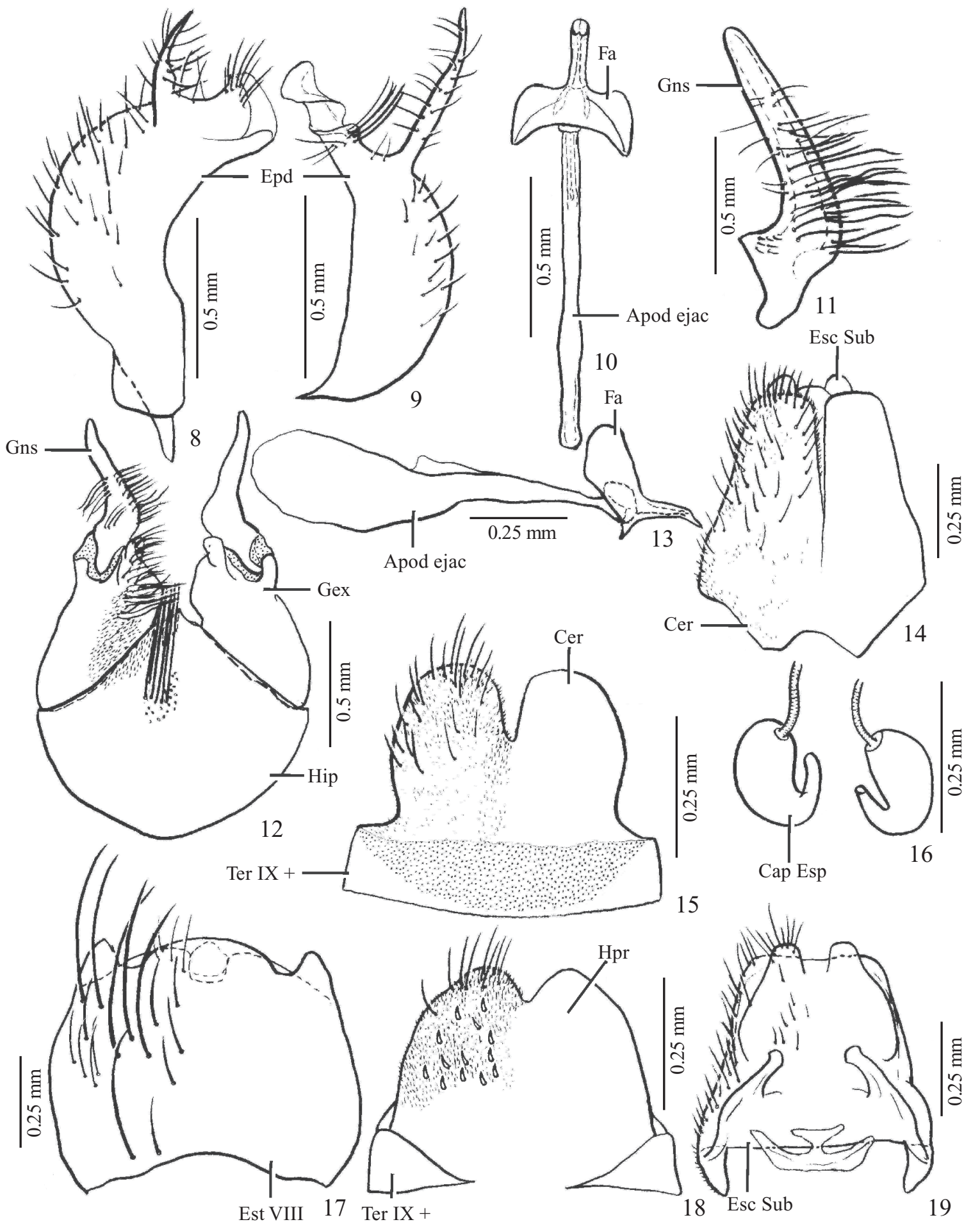

Figs. 8-19. Ommatius conus Scarbrough. Holótipo macho (Figs. 8-14, 19); parátipo fêmea (Figs.: 15-18). 8. Epândrio em vista dorsal; 9. Epândrio em vista ventral; 10. Falo em vista dorsal; 11. Gonóstilo em vista lateral; 12. Hipândrio, gonocoxito e gonóstilo em vista ventral; 13 . Falo em vista lateral; 14. Cercos; 15. Tergito IX $+X$ e cercos em vista dorsal; 16. Cápsulas das espermatecas; 17. Esternitos VIII; 18. Hipoprocto e Tergito IX+X; 19. Esclerito subepandrial. Abreviaturas: Apod ejac: Ápodema ejaculador; Cer: Cercos; Epd: Epândrio; Cap Esp: Cápsulas das espermatecas; Fa: Falo; Gcx: Gonocoxito; Gns: Gonóstilo; Hip: Hipândrio; Hpr: Hipoprocto; Est VIII: Esternito VIII; Esc Sub: Esclerito subepandrial; Ter IX+X: Tergito IX+X.

Terminália. Macho: epândrio com uma projeção préapical longa e pontiaguda (Figs. 8, 9); ápodema ejaculador medindo cerca de $3 \mathrm{x}$ o comprimento do falo (Fig. 10, 13); ápice do falo pontiagudo em vista lateral (Fig. 13); apódema ejaculador largo na região mediobasal e com uma crista membranosa dorsal (Fig. 13); gonóstilo em forma de bumerangue com várias cerdas finas na margem interna (Figs. 11, 12); gonocoxito com uma projeção apical na margem inter- 
na (Fig. 12); hipândrio com cerdas longas na porção mediana, região posterior triangular (Fig. 12).

Fêmea: cápsulas das espermatecas com o ápice afilado e recurvado (Fig. 16); hipoprocto com cerdas espiniformes (Fig. 18).

Variação: Ommatius conus foi descrito baseado apenas no holótipo macho e um parátipo fêmea, ambos do estado do Rio de Janeiro. Neste trabalho, foram encontrados mais dois espécimes, um macho e uma fêmea, da localidade tipo (Nova Friburgo). No espécime adicional macho ocorre uma pequena variação em relação ao holótipo. O místax possui sete cerdas escuras (holótipo com seis e algumas cerdas finas, pequenas e escuras medindo cerca da metade do comprimento das demais), fêmur posterior com três cerdas escuras anteriores (holótipo com três cerdas amarelas e uma escura), tíbia mediana com seis cerdas pretas e grossas anteriores (holótipo com cinco cerdas pretas e grossas), e o comprimento do corpo medindo 15,2 mm e asa 11,5 mm (holótipo medindo $13.8 \mathrm{~mm}$ e asa 11,1 mm). Fêmea: Místax com dez cerdas castanhas longas, fêmur mediano sem cerda posterodorsal pré-apical; fêmur posterior com duas cerdas anteriores e cerdas anteroventrais pretas presentes no 1/3 basal; tarso anterior com duas cerdas amareladas. No parátipo fêmea, místax com seis cerdas longas, castanhas e cerdas finas e castanhas esparsas; fêmur mediano com cerda posterodorsal pré-apical preta; fêmur posterior com três cerdas anteriores e sem cerdas anteroventrais pretas no $1 / 3$ basal; tarso anterior com uma cerda amarelada.

Registros Geográficos: BRASIL - Rio de Janeiro.

Material examinado: Holótipo macho. Mury, Nova Friburgo, Rio de Janeiro - Br. [BRASIL], 1-2.xi.1970, Gred \& Guimarães col. [coletor]/Holotype Ommatius conus Scarbrough (MZUSP).

Parátipo: mesmo local e coletor do holótipo, exceto 12.xi.1970/Allotype Ommatius conus Scarbrough (1) MZUSP).

Material adicional: mesmo local, data e coletor do parátipo/Ommatius conus Det.[Determinante] R. Vieira, 2007 (10' MZUSP); mesmo local, data e coletor do holótipo exceto xii.1974/Ommatius conus Det. [Determinante] R. Vieira, 2008 (1) MZUSP).

\section{Ommatius exilis Curran}

(Figs. 20-31)

Ommatius exilis Curran, 1928: 5; Bromley 1946: 112 (catálogo); Carrera 1960: 167; Hull 1962: 435; Martin \& Papavero 1970: 59 (catálogo); Lamas 1972: 312 (catálogo); Scarbrough 2002: 207, figs. 169, 191199; Papavero 2009: 49 (catálogo).

Ommatius exilus Scarbrough, 2002: 208-209, figs. 169, 191-199, erro

Diagnose. Macho: maioria das cerdas anteroventrais do fêmur posterior pretas; gonocoxito com uma projeção digitada (Figs. 20, 23); hipândrio com uma projeção medioapical alongada entre as bases do gonocoxito (Figs. 23, 26). Fêmea: cápsulas das espermatecas alongadas, com uma constrição mediana e ápice pontiagudo (Fig. 24); esternito VIII com a margem posterior truncada medialmente e bem proeminente (Fig. 29).

Terminália. Macho: margem anterior do epândrio reta (Fig. 21); margem posterior do gonóstilo côncava (Fig. 22); falo em vista dorsal com a margem anterior sinuosa com reentrância medial mais aprofundada (Fig. 25); esclerito subepandrial com uma protuberância anterolateral arredondada (Fig. 28); ápice do falo com textura escamiforme na região lateroventral (Fig. 27).

Fêmea: tergito IX+X largo (Figs. 30, 31); hipoprocto com cerdas espiniformes (Fig. 30).

Comentários: Curran (1928) descreveu O. exilis baseado em um holótipo e um parátipo, ambos machos, provenientes da "Chapada" - possivelmente Chapada dos Guimarães em Mato Grosso - (Papavero 2009). Carrera (1960) registrou duas fêmeas e três machos de $O$. exilis provenientes dos estados do Rio de Janeiro e São Paulo, porém não descreveu a fêmea e tampouco fez algum comentário. Lamas (1972) registrou O. exilis para Loreto (Pucallpa, 200m) no Peru. Scarbrough (2002) ampliou o registro de O. exilis para Rondônia e Argentina, além disso descreveu a fêmea baseado em três espécimes, dois do estado de Rondônia e um do Mato Grosso, relatando que o grupo de espécies holosericeus era registrado para Galápagos, Brasil e região norte da Argentina. Vale ressaltar que Scarbrough (2002) não mencionou os trabalhos de Carrera (1960) e Lamas (1972).

Neste trabalho, $O$. exilis é registrado pela primeira vez para o estado de Goiás. O espécime adicional fêmea difere da descrição de Scarbrough (2002) por possuir as regiões dorsal, anterior e posterior dos fêmures anterior e mediano castanhas a castanho-escuras e ventralmente amarelados, fêmur mediano com duas cerdas finas anteroventrais e a metade apical do fêmur posterior preta. De acordo com Scarbrough (2002), a fêmea de $O$. exilis possui a maior parte dos fêmures anterior e mediano amarelada, exceto pela $1 / 2$ a $2 / 3$ da região anterodorsal e da pequena parte apical castanha posteriormente, fêmur mediano com três a quatro cerdas finas anteroventrais e o 1/3 apical do fêmur posterior castanho.

Registros Geográficos: PERU, BRASIL - Rondônia, Mato Grosso, Tocantins, Goiás (novo registro), Rio de Janeiro, São Paulo; ARGENTINA.

Material examinado: Jataí, Goyas \{Goiás\}, BRASIL/F. M. Oliveira, xi.[19]72/Q/MNRJ 7661/Ommatius exilis Det. [Determinante] R. Vieira, 2007 (10', 1Q MNRJ).

\section{Ommatius holosericeus Schiner}

(Figs. 32-43)

Ommatius holosericeus Schiner, 1867: 411; Williston 1891: 90 (catálogo); Kertész 1909: 308 (catálogo); Bromley 1946: 112 (catálogo); Hull 1962: [224]: 435; Martin \& Papavero 1970: 59 (catálogo); Scarbrough 2002: 210, figs. 170, 200-208; Papavero 2009: 49 (catálogo).

Diagnose. Macho: três a cinco cerdas marginais escutelares; fêmures totalmente pretos, às vezes levemente avermelhados; 


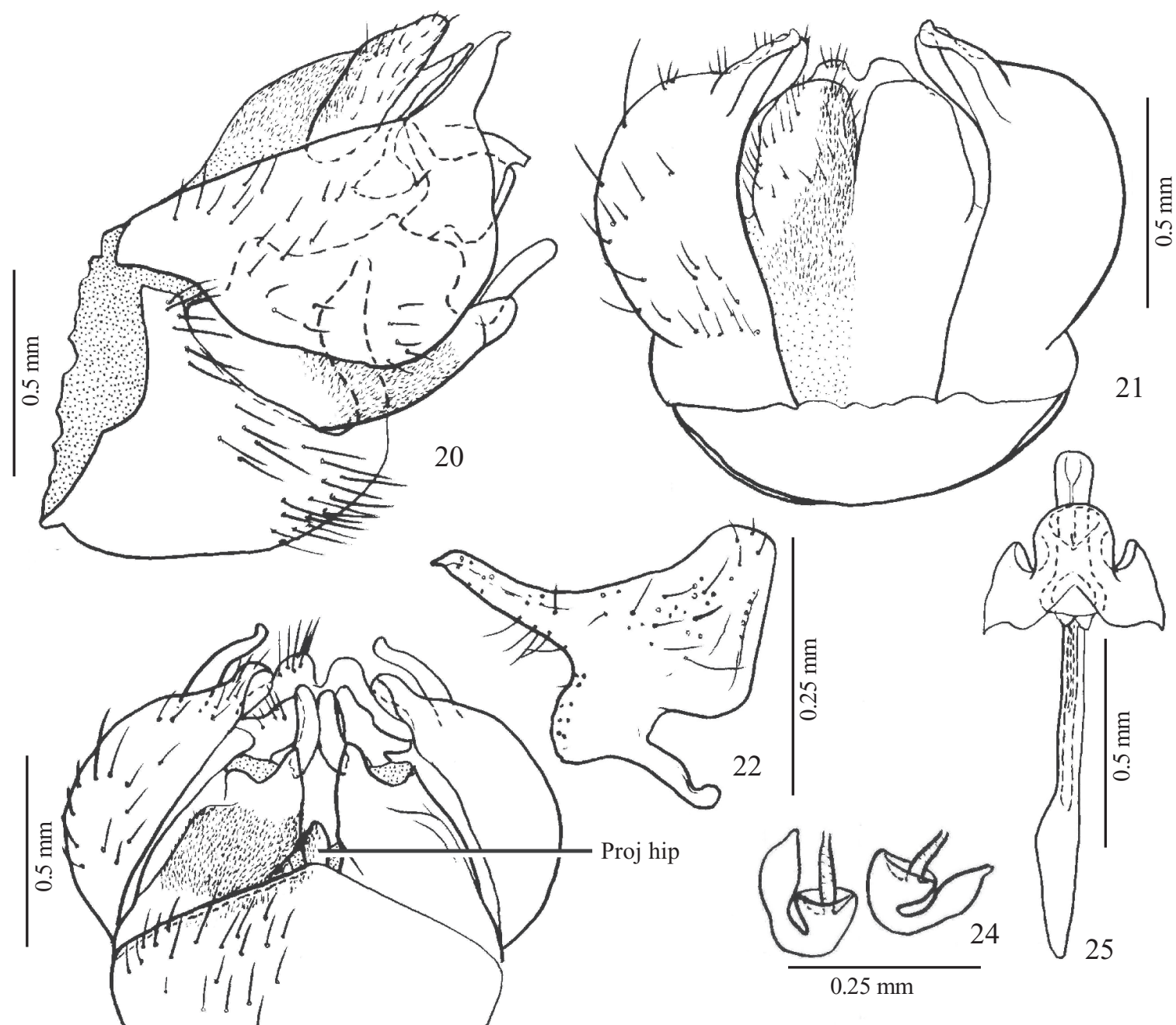

21 

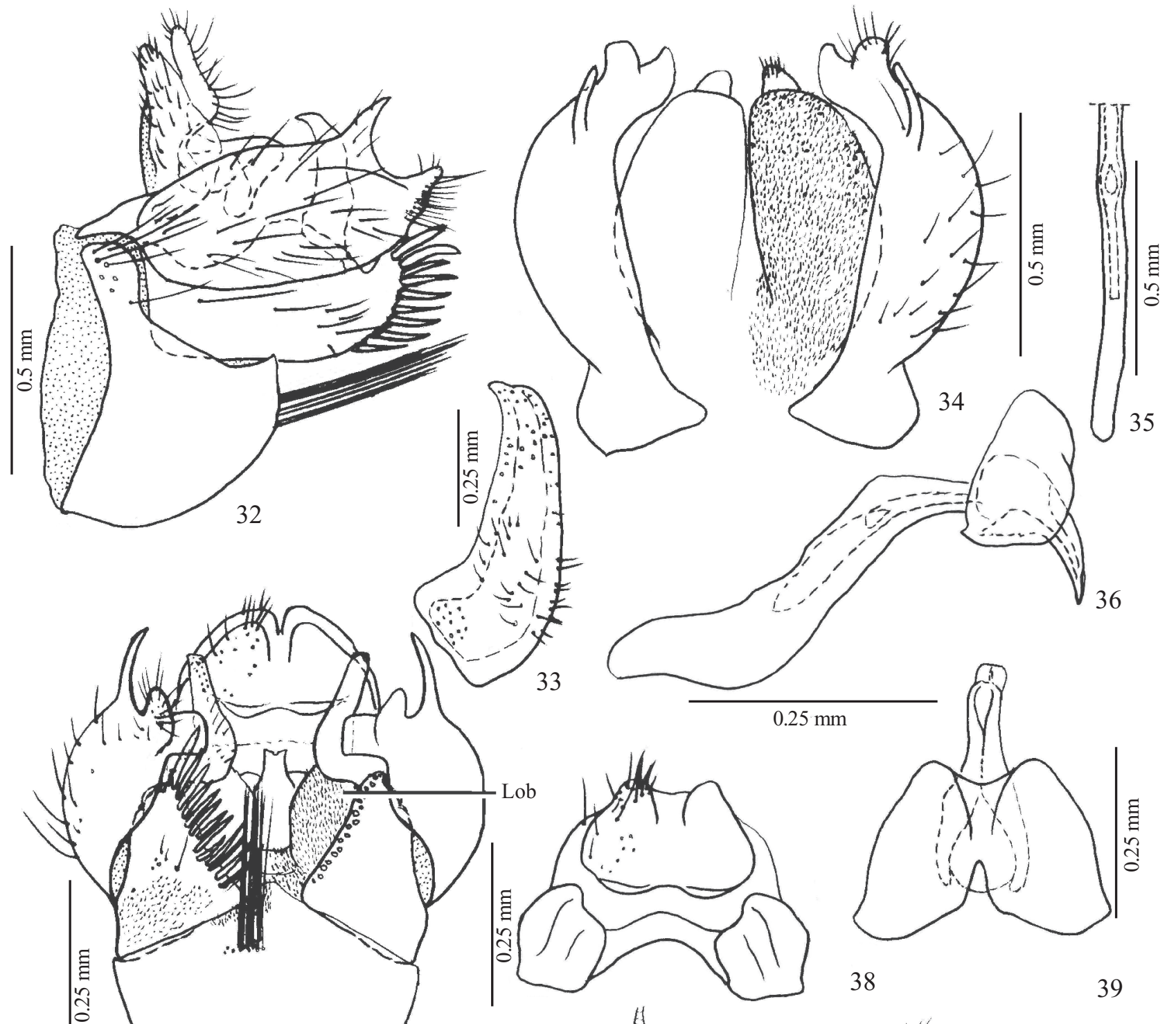

38

39
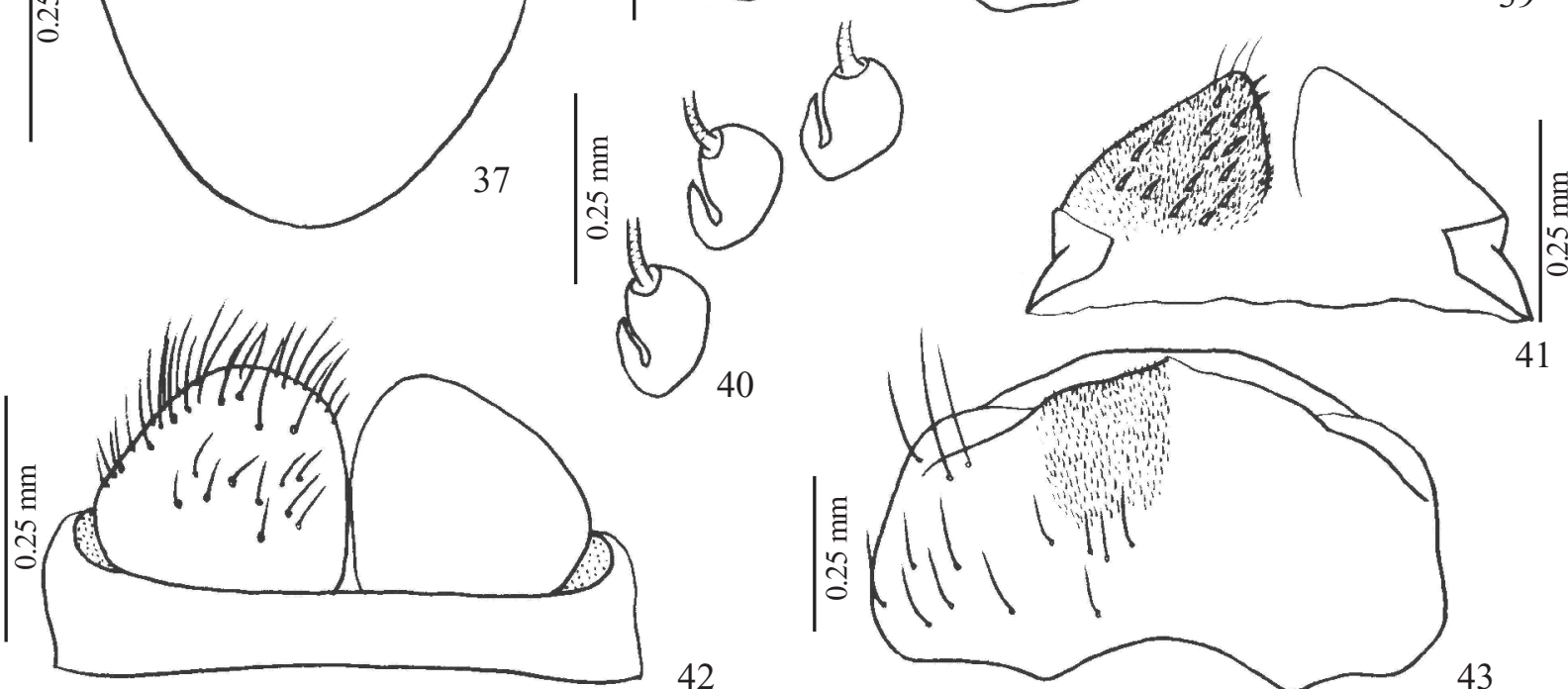

40

Figs. 32-43. Ommatius holosericeus Schiner. Macho (Figs. 32-39); Fêmea (Figs.: 40-43). 32. Terminália em vista lateral; 33. Gonóstilo em vista lateral; 34. Terminália em vista dorsal; 35. Apódema ejaculador em vista dorsal; 36. Falo em vista lateral; 37 . Terminália em vista ventral; 38. Esclerito subepandrial; 39. Falo em vista dorsal; 40. Cápsulas das espermatecas; 41. Hipoprocto e Tergito IX+X; 42. Tergito IX+X e cercos em vista dorsal; 43. Esternito VIII. Abreviaturas: Lob: Lobo membranoso. 
gonocoxito com numerosas cerdas grossas (Figs. 32, 37); membrana ligando os gonocoxitos com um grande lobo em cada lateral (Fig. 37); esclerito subepandrial com duas protuberâncias na porção anterolateral (Fig. 38). Fêmea: quatro a seis cerdas marginais escutelares; tergito IX $+X$ largo (Fig. 42); esternito VIII com três reentrâncias na margem anterior, a mediana maior que as laterais, margem posterior levemente proeminente na região medial (Fig. 43).

Terminália. Macho: gonóstilo em formato de garra (Fig. 33); epândrio possui o ápice bifurcado (Fig. 34) e uma projeção pré-apical, longa, estreita e pontiaguda (Figs. 34, 37); ápodema ejaculador medindo cerca de $3 \mathrm{x}$ o comprimento do falo (Figs. 35, 36, 39); apódema ejaculador sinuoso (Fig. 36); ápice do falo pontiagudo e inclinado ventralmente (Fig. 36); hipândrio com cerdas longas na porção pré-apical e com a margem posterior triangular (Fig. 37).

Fêmea: cápsulas das espermatecas com uma constrição pré-apical, porção basal larga e porção apical estreita (Fig. 40); hipoprocto com cerdas espiniformes (Fig. 41).

Variação: um espécime macho proveniente do Rio de Janeiro com seis cerdas marginais escutelares longas e grossas e os fêmures castanhos.

Registros Geográficos: BRASIL - Espírito Santo, Rio de Janeiro, São Paulo, Santa Catarina.

Material examinado: DPT $^{\circ}$ [Departamento] ZOOL [Zoologia] UF [Universidade Federal]-PARANÁ/STA. [Santa] Tereza - E. STO [Espírito Santo] BRASIL, 1-3.ii.[19]68 C. \& C. T. Elias leg./Ommatius holosericeus Schiner, DT. [Determinante] A. Scarbrough (2@ DZUP); S.J. [São João de] Petrópolis - ES [Espírito Santo], BRASIL, 12.xi.[19]64, C. Elias, Leg./ Ommatius holosericeus Schiner, DT. [Determinante] A. Scarbrough (10 DZUP); Nova Friburgo, RJ [Rio de Janeiro], BRASIL, i.1970, Guimarães, Papavero col. [coletor]/Ommatius holosericeus det. [Determinante] R. Vieira, 2006 (10 MZUSP); [BRASIL] Nova Friburgo, Estado do Rio [Janeiro], 900 m, i.1946, Wygod.[zinski] col.[etor]/Ommatius holosericeus Schiner DT. [Determinante] A. Scarbrough (20" MZUSP); [BRASIL], Corcovabo \{Corcovado\}, Rio [de Janeiro] D.F. \{antiga sede do Distrito Federal do Brasil\}, i.1948, Coll. Wygodzinski/Ommatius holosericeus Schiner DT. [Determinante] A. Scarbrough (10 DZUP); Mury, Nova Friburgo, Rio de Janeiro - Br. [BRASIL], xii.1965, Gred \& Guimarães col. [coletor]/Ommatius holosericeus Schiner DT. [Determinante] A. Scarbrough (1ㅇ DZUP); [BRASIL] São Paulo, M.[ogi] das Cruses \{Cruzes\}, M. Carrera col.[etor], i.1939/Ommatius holosericeus Schiner, DT. [Determinante] A. Scarbrough (10', 10 MZUSP); [BRASIL] São Paulo, M.[ogi] das Cruses \{Cruzes\}, M. Carrera col.[etor], ii.1938/Ommatius holosericeus Schiner DT. [Determinante] A. Scarbrough (1@ MZUSP).

\section{Ommatius narrius Scarbrough}

$$
\text { (Figs. 44-54) }
$$

Ommatius narrius Scarbrough, 2002: 214, figs. 171, 209-217; Papavero 2008: 50 (catálogo).

Diagnose. Macho: epândrio com o ápice truncado (Fig. 44); gonóstilo podiforme (Fig. 45); gonocoxito com uma protuberância lateral pequena e uma projeção medioapical longa e estreita possuindo cerdas finas e amareladas (Fig. 49). Fêmea: esternito VIII com as margens laterais e medioapical arredondadas e levemente proeminentes (Fig. 53).
Terminália. Macho: cercos com o ápice truncado (Fig. 48); ápice do falo inclinado ventralmente em vista lateral (Fig. 46). Falo com ápice largo em vista dorsal (Fig. 47); esclerito subepandrial com a margem posterior em forma de U e com uma fileira de cerdas finas na porção medioapical (Fig. 51).

Fêmea: tergito IX $+\mathrm{X}$ largo com a margem anterior convexa na porção mediana (Fig. 54); cápsulas das espermatecas com 2/3 basal largo e 1/3 apical estreito com o ápice terminando em ponta (Fig. 50); hipoprocto com cerdas espiniformes (Fig. 52).

Variação: Em um parátipo fêmea de Campos do Jordão, São Paulo, há duas cerdas anepimerais, sendo uma mais conspícua e 3x mais espessa do que a outra. No holótipo e nos demais parátipos há somente uma cerda anepimeral.

Registros Geográficos: Brasil - Minas Gerais, Espírito Santo, Rio de Janeiro, São Paulo.

Material examinado: Holótipo macho: [BRASIL] Horto Flor[estal] [São Paulo], [São Paulo] 17.ii.[19]44, Ramalho [coletor]/Holotype Ommatius narrius Scarbrough (MZUSP).

Parátipos: [BRASIL], Minas Geraes \{Gerais\}, Belo Horizonte, i.[19]56, A. B. Machado [Coletor]/Paratype Ommatius narrius Scarbrough (10" MZUSP); DPT $^{\circ}$ [Departamento] ZOOL [Zoologia] UF [Universidade Federal]-PARANÁ/Santa Teresa-ES [Espírito Santo] BRASIL, 8.i.1966 C. \& C. T. Elias leg./Paratype Ommatius narrius Scarbrough (10 MZUSP); mesmo local e coletor do holótipo, exceto 12.ii.[19]44/Allotype Ommatius narrius Scarbrough (1) MZUSP); Floresta da Tijuca, Distrito Federal \{antiga sede do Distrito Federal do Brasil\} [Rio de Janeiro], BRASIL, i.[19]51, C. A. C. Seabra, Col.[etor]/28017/Paratype Ommatius narrius Scarbrough (10" MZUSP); [BRASIL], S.[ão] [São Paulo], C.[ampos] [do] Jordão, xii.[19]55, J. Lane col.[etor]/Paratype Ommatius narrius Scarbrough (2@ MZUSP); [BRASIL], S. Paulo [São Paulo], Camp.[os] do Jordão, xii.[1]945, M. P. Barreto col.[etor]/Paratype Ommatius narrius Scarbrough (10" MZUSP).

Material adicional: BRASIL, Minas Gerais, Poços de Caldas, Retiro Branco, 20.ii.1967, J. Becker, O. Roppa \& O. Leoncini cols.[Coletores]/ Becker/MNRJ 7648/Q/Ommatius narrius det. [Determinante] R. Vieira, 2007 (1\% MNRJ); mesmos dados exceto 1.ii.1968, J. Becker \& O. Leoncini cols.[Coletores]/Ommatius sp. M. S. Couri det, [Determinante] 90/MNRJ 7649/Q/Ommatius narrius det. [Determinante] R. Vieira, 2007 (1QMNRJ); BRASIL, Minas Gerais, Poços de Caldas, Morro do Ferro, xi.1965, J. Becker \& O. Roppa cols.[Coletores]/Becker/MNRJ 7677/Ommatius narrius det. [Determinante] R. Vieira, 2007 (1@ MNRJ); Petrópolis, Tq. E.[stado] do Rio [de Janeiro], H. S. Lopes, 8.xi.[19]69/MNRJ 7655/O'/Ommatius narrius det. [Determinante] R. Vieira, 2007 (19 MNRJ).

\section{Ommatius simulans Scarbrough}

(Figs. 55-66)

Ommatius simulans Scarbrough, 2002: 217, figs. 172, 218-226; Papavero 2009: 52 (catálogo).

Diagnose. Macho: fêmur posterior com todas ou a maioria das cerdas anteroventrais amareladas; hipândrio com uma projeção medioapical longa entre as bases dos gonocoxitos (Figs. 57, 61); gonocoxito com uma projeção longa na margem interna possuindo um dígito apical curto e grosso (Fig. 61); cercos com uma reentrância na região mediana da margem externa (Fig. 66). Fêmea: cápsulas das espermatecas constritas na região mediana, ápice arredondado (Fig. 62); tergito IX $+\mathrm{X}$ com as margens laterais proeminentes (Fig. 65). 


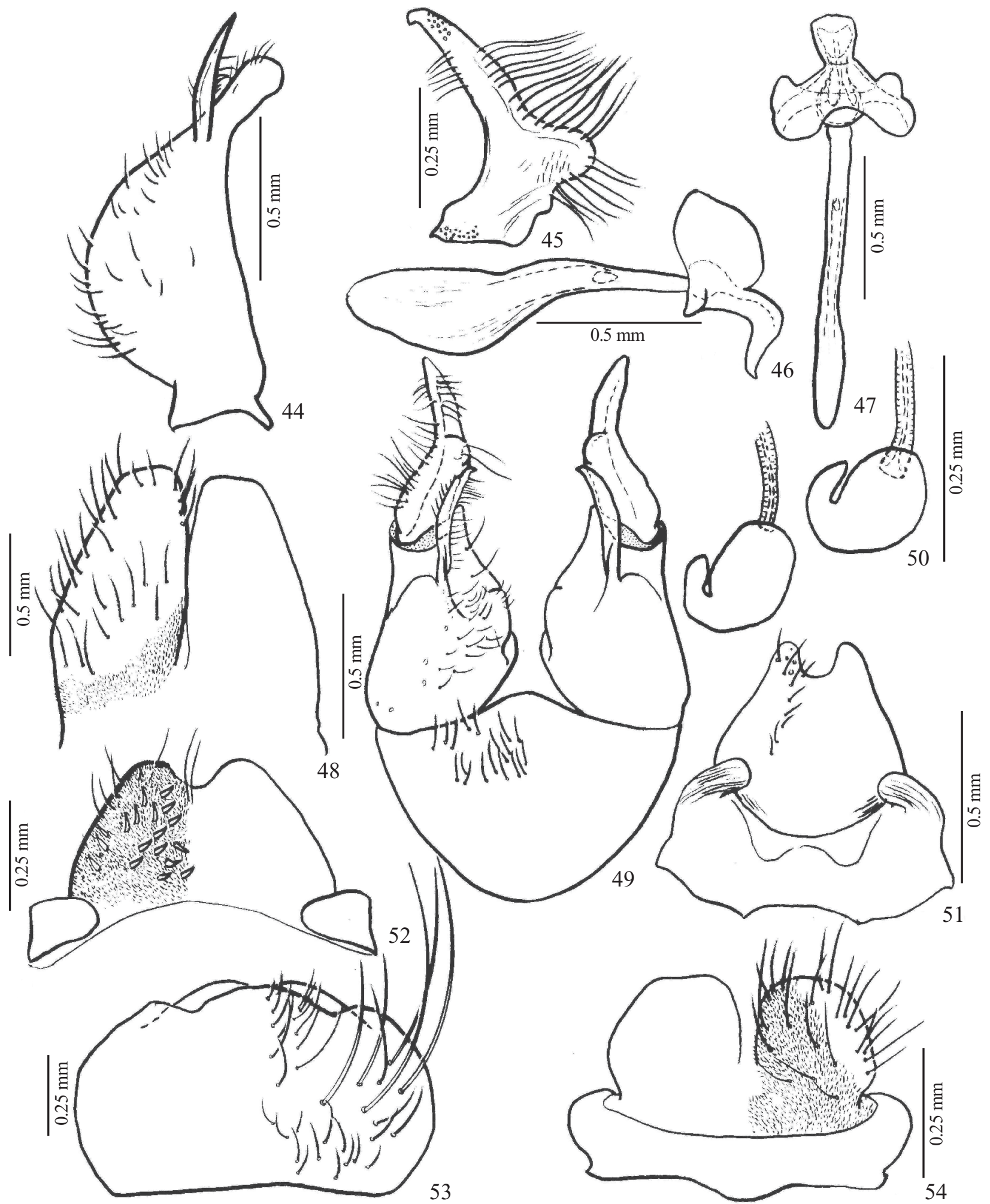

Figs. 44-54. Ommatius narrius Scarbrough. Parátipo macho (Figs. 44-49, 51); parátipo fêmea (Figs.: 50, 52-54). 44. Epândrio em vista dorsal; 45. Gonóstilo em vista lateral; 46. Falo em vista lateral; 47. Falo em vista dorsal; 48. Cercos; 49. Hipândrio, gonocoxito e gonóstilo em vista ventral; 50. Cápsulas das espermatecas; 51. Esclerito subepandrial; 52. Hipoprocto e Tergito IX+X; 53. Esternito VIII; 54. Tergito IX+X e cercos em vista dorsal.

Terminália. Macho: ápice do epândrio triangular (Fig. 55); epândrio com uma projeção pré-apical longa (Fig. 55); esclerito subepandrial com a porção basolateral desenvolvi- da (Fig. 63); gonóstilo em forma de machado (Fig. 59); apódema ejaculador com uma crista membranosa dorsobasal (Fig. 58); ápice do falo tubular e alongado (Figs. 56, 58). 

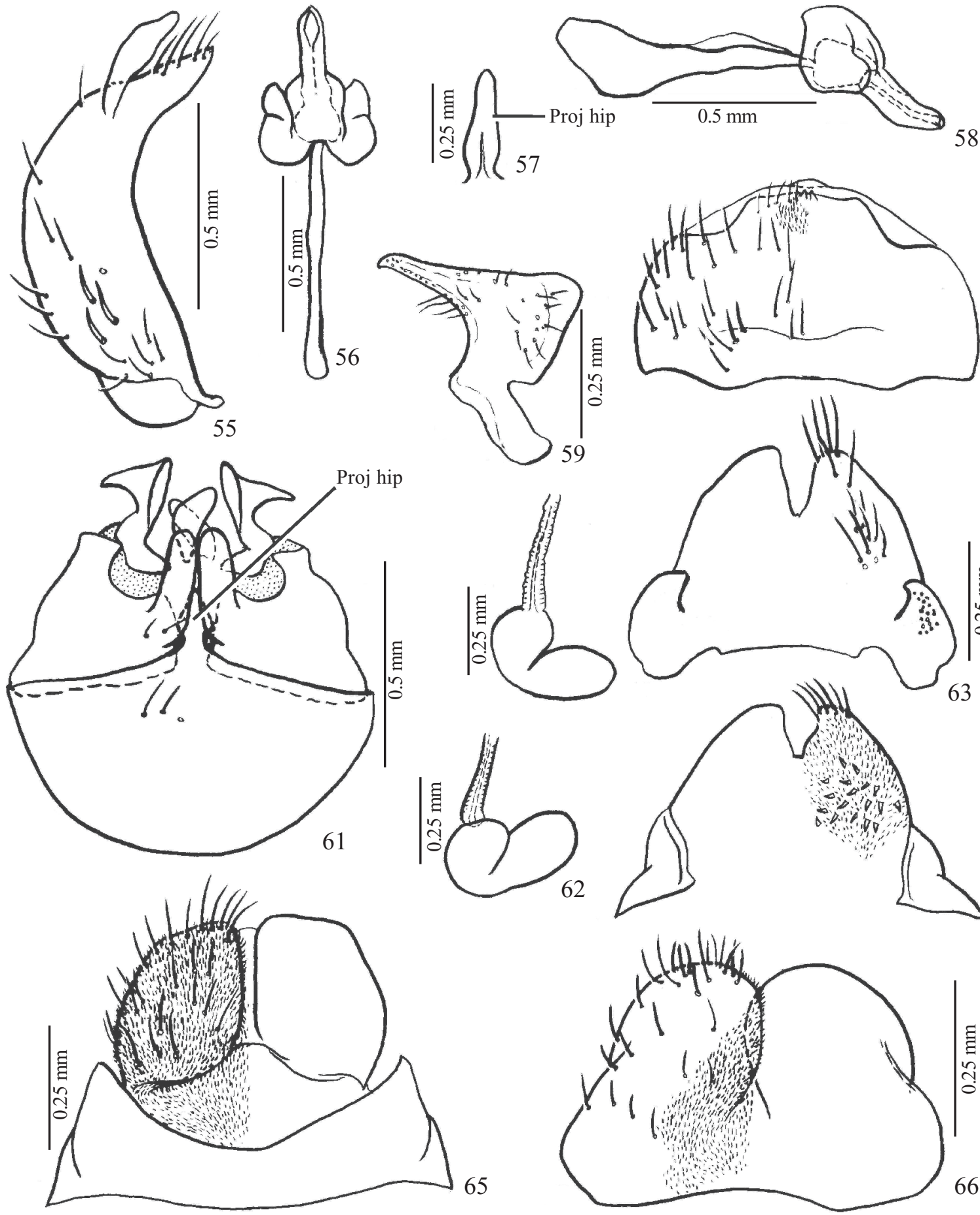

\section{8}
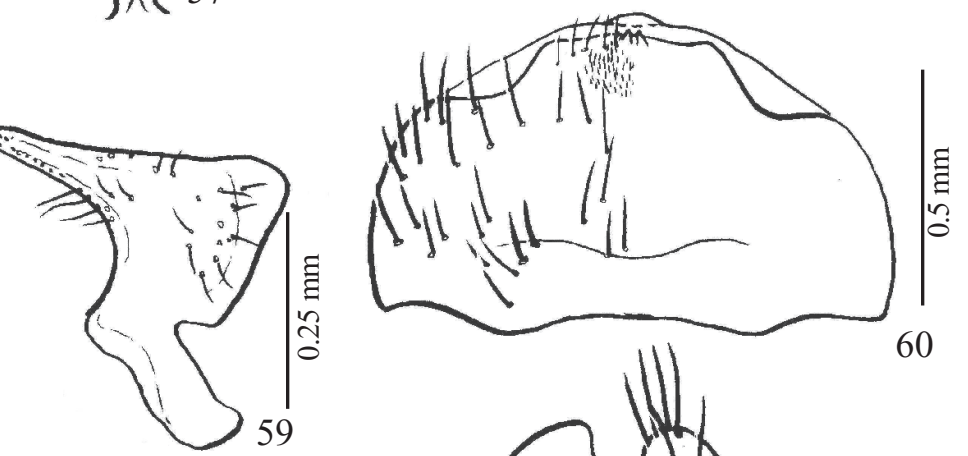

60
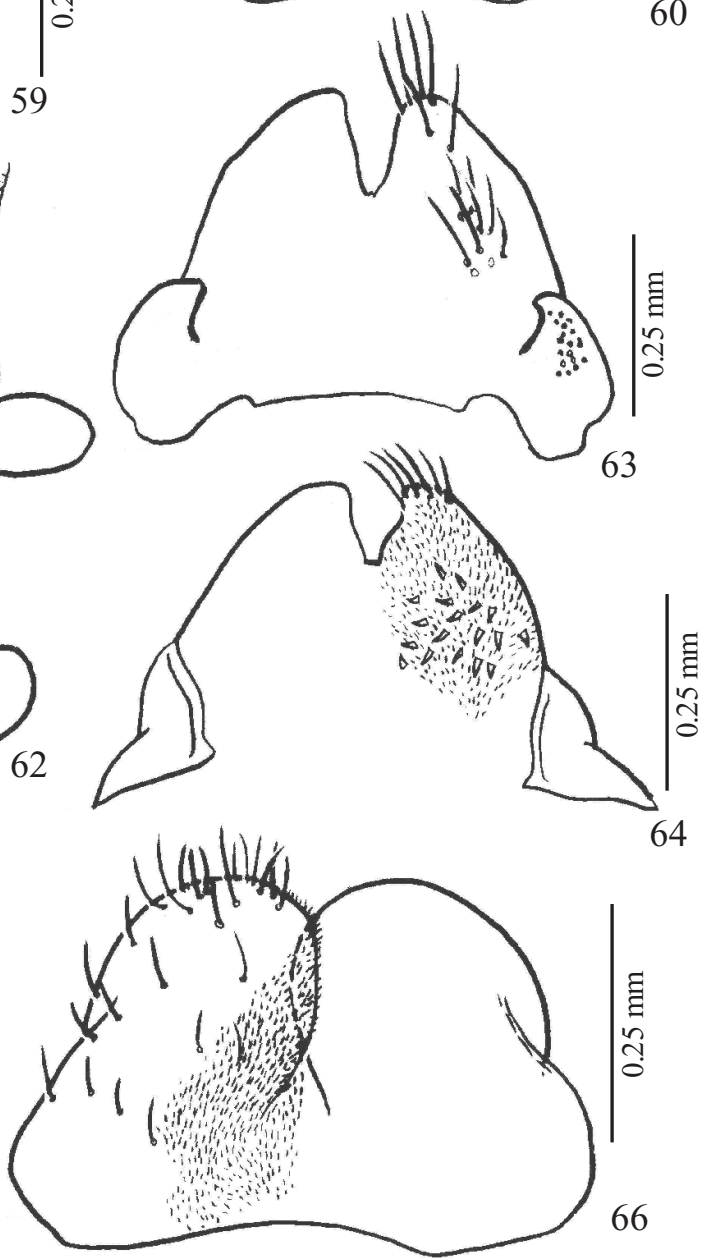

Figs. 55-66. Ommatius simulans Scarbrough. Parátipo macho (Figs. 55-59, 61, 63); parátipo fêmea (Figs.: 60, 62, 64-66). 55 . Epândrio vista dorsal; 56. Falo em vista dorsal; 57. Ápice do hipândrio; 58. Falo em vista lateral; 59. Gonóstilo em vista lateral; 60. Esternito VIII; 61. Hipândrio, gonocoxito e gonóstilo em vista ventral; 62. Cápsulas das espermatecas; 63. Esclerito subepandrial; 64. Hipoprocto e Tergito IX+X; 65. Tergito IX+X e cercos em vista dorsal; 66. Cercos. Abreviaturas: Proj hip: Projeção do hipândrio.

Fêmea: esternito VIII com borda medioposterior proeminente, com três reentrâncias na margem anterior (Fig. 60); hipoprocto com cerdas espiniformes (Fig. 64).

Comentários: $O$. simulans é registrada pela primeira vez para o estado da Bahia, primeiro registro do grupo holosericeus para a região Nordeste do Brasil.
Registros Geográficos: Brasil: Bahia (novo registro), Goiás, Minas Gerais, São Paulo.

Material examinado: Holótipo macho: [BRASIL], Goiás, Corumbá [de Goiás], F. [azenda] Monjolinho, xi.1945, Barreto col.[coletor]/Holotype Ommatius simulans Scarbrough (MZUSP). 
Parátipos: mesmo local, data e coletor do holótipo/Paratype Ommatius simulans Scarbrough (10', 1\% MZUSP); mesmo local, data e coletor do holótipo/Allotype Ommatius simulans Scarbrough (1O MZUSP); [BRASIL], xi.[19]31, Goyaz \{Goiás\}, (Viannopolis) \{Vianópolis\}, Coll. R. Spitz/ Paratype Ommatius simulans Scarbrough (1@ MZUSP); [BRASIL], Est. [ado] de Minas [Gerais], Arceburgo, F. Fortaleza, xii.[1]946, Barreto col. [etor]/Paratype Ommatius simulans Scarbrough (2Q MZUSP); [BRASIL], Minas Gerais, Belo Horizonte, x.[19]51, Pde [Padre] Pereira [coletor]/ Paratype Ommatius simulans Scarbrough (10 MZUSP); Ibiá - MG [Minas Gerais], BR [BRASIL], 11.x.1965, C. Elias/Leg/n. sp. nov.[ear] exilis Curran/Paratype Ommatius simulans Scarbrough (10' DZUP); [BRASIL], S. P. [São Paulo] - Magda, Faz.[enda] S. Eco., J. Lane [coletor], xii.1957/ Paratype Ommatius simulans Scarbrough (10 MZUSP); [BRASIL], São Paulo, Guatapará, i.1945, M. Carrera [coletor]/Paratype Ommatius simulans Scarbrough (10 MZUSP); BRASIL, SP [São Paulo], Ribeirão Preto, Rio Tamanduá, x.1953, M. P. Barreto [coletor], (abdômen perdido)/Paratype Ommatius simulans Scarbrough (1@ MZUSP); Cassia bos $\{\operatorname{dos}\}$ Coqueiros, Cajuru, SP [São Paulo], Brasil, iii.1955, M. P. Barreto [coletor]/Paratype Ommatius simulans Scarbrough (1@ MZUSP); [BRASIL], Faz. [enda] Itaquerê, Tabatinga, SP [São Paulo], 29.xi.1963, K. Lenko col. [etor]/ Paratype Ommatius simulans Scarbrough (10̛, 1Q MZUSP).

Material adicional: Encruzilhada, Divisa 960 m, Bahia, BRASIL/Seabra \& Roppa [coletores], xi.[19]72/O' \{O\}\}/MNRJ 7668/Ommatius simulans Det. [Determinante] R. Vieira, 2007 (1Q MNRJ).

\section{AGRADECIMENTOS}

O primeiro autor agradece a Aubrey Scarbrough pela ajuda ao longo dos anos na taxonomia de Ommatius. Aos curadores Augusto Loureiro Henriques (INPA), Carlos Lamas (MZUSP), Márcia Couri (MNRJ) e Luciane Marinoni (DZUP), pelo empréstimo do material examinado neste trabalho. Aos revisores anônimos pelas sugestões no manuscrito. Ao CNPq pela concessão da bolsa de Mestrado (RV) e Produtividade em Pesquisa (JAR - processo 300305/2007-9).

\section{REFERÊNCIAS}

Bromley, S. W. 1946. The robber flies of Brazil (Asilidae: Diptera), p. 103120. In: Livro de homenagem a Romualdo Ferreira d'Almeida. São Paulo, Sociedade Brasileira de Entomologia, 349 p.

Carrera, M. 1960. Asilidae (Diptera) da coleção Seabra. Arquivos de Zoologia 11: 147-170.

Cumming, J. M. \& D. M. Wood. 2009. Adult morphology and terminology, p. 9-50. In: B. V. Brown; A. Borkent; J. M. Cumming; D. M. Wood; N. E. Woodley \& M. A. Zumbado (eds.). Manual of Central American Diptera, Volume 1, Ottawa, National Research Council Research Press, 950 p.

Curran, C. H. 1928. New species of Ommatius from America, with key (Asilidae, Diptera). American Museum Novitates 327: 1-6.

Hull, F. M. 1962. Robber Flies of the World: The Genera of the Family Asilidae. Bulletin of the United States National Museum, Part 2, 224: 431-906.

Kertész, C. 1909. Catalogus dipterorum hucusque descriptorum (IV). Oncodidae, Nemestrinidae, Mydaidae, Asilidae 4. Museum Nationale Hungaricum: 49-348.

Lamas, G. 1972. A catalogue of Peruvian Asilidae (Diptera), with keys to identification and descriptions of two new species. Revista Peruana de Entomologia 15: 304-316.

Martin, C. H. \& N. Papavero. 1970. A catalogue of the Diptera of the Americas south of the United States. Family Asilidae. Museu de Zoologia: 1-139.

Papavero, N. 2009. Catalogue of Neotropical Diptera. Asilidae. Neotropical Diptera 17: 1-178.

Scarbrough, A. G. 2002. Synopsis of the Neotropical holosericeus complex of the genus Ommatius Wiedemann (Diptera): ampliatus and holosericeus species group. Transactions of the American Entomological Society 128: 133-222.

Schiner, J. R. 1867. Neue oder weniger bekannte Asiliden des K. Zoologischen Hofcabinetes in Wien. Ein Beitrag zur Kenntnis der Asiliden. Verhandlungen der zoologisch-botanischen Gesellschaft in Wien 17: 355-412.

Williston, S.W. 1891. Catalogue of the described species of South American Asilidae. Transactions of the American Entomological Society 18: 67-91.

Received 2/3/2011; accepted 10/10/2011

Editor: Silvio Shigueo Nihei 